University of Wollongong

Research Online

Australian Institute for Innovative Materials -

Papers

Australian Institute for Innovative Materials

$1-1-2020$

Graphitic carbon nitride with thermally-induced nitrogen defects: an efficient process to enhance photocatalytic $\mathrm{H}$ 2production performance

Guangzhi Dong

University of Wollongong

Yun Wen

Huiqing Fan

Chao Wang

Zhenxiang Cheng

University of Wollongong, cheng@uow.edu.au

See next page for additional authors

Follow this and additional works at: https://ro.uow.edu.au/aiimpapers

Part of the Engineering Commons, and the Physical Sciences and Mathematics Commons

Research Online is the open access institutional repository for the University of Wollongong. For further information contact the UOW Library: research-pubs@uow.edu.au 


\title{
Graphitic carbon nitride with thermally-induced nitrogen defects: an efficient process to enhance photocatalytic $\mathrm{H} 2$ production performance
}

\author{
Abstract \\ Graphitic carbon nitride ( $\mathrm{g}-\mathrm{C} 3 \mathrm{~N} 4, \mathrm{CN}$ ) with nitrogen vacancies was synthesized by a controlled thermal \\ etching method in a semi-closed air-conditioning system. The defect-modified g-C3N4shows an excellent \\ photocatalytic performance demonstrated by water splitting under visible light irradiation. With proper \\ heat-treatment durations such as $2 \mathrm{~h}(\mathrm{CN} 2)$ and $4 \mathrm{~h}(\mathrm{CN} 4)$ at $550{ }^{\circ} \mathrm{C}$, the hydrogen production rates \\ significantly increase to $100 \mu \mathrm{mol}$ h-1and $72 \mu \mathrm{mol}$ h-1, which are 11 times and 8 times the rate of the \\ pristine $\mathrm{CN}(8.8 \mu \mathrm{mol} \mathrm{h}-1)$ respectively. The excellent hydrogen production performance of nitrogen defect \\ modified CN2 is due to the synergy effect of the decreased band gap, enlarged specific surface area and \\ increased separation/migration efficiency of photoinduced charge carriers. This simple defect \\ engineering method provides a good paradigm to improve the photocatalytic performance by tailoring the \\ electronic and physical structures of g-C3N4. \\ Disciplines \\ Engineering | Physical Sciences and Mathematics

\section{Publication Details} \\ Dong, G., Wen, Y., Fan, H., Wang, C., Cheng, Z., Zhang, M., Ma, J. \& Zhang, S. (2020). Graphitic carbon \\ nitride with thermally-induced nitrogen defects: an efficient process to enhance photocatalytic \\ H2production performance. RSC Advances, 10 (32), 18632-18638.

\section{Authors} \\ Guangzhi Dong, Yun Wen, Huiqing Fan, Chao Wang, Zhenxiang Cheng, Mingchang Zhang, Jiangwei Ma, \\ and Shujun Zhang
}




\title{
RSC Advances
}

Check for updates

Cite this: RSC Adv., 2020, 10, 18632

Received 14th February 2020

Accepted 9th May 2020

DOI: $10.1039 / \mathrm{d} 0 \mathrm{ra01425g}$

rsc.li/rsc-advances

\section{Graphitic carbon nitride with thermally-induced nitrogen defects: an efficient process to enhance photocatalytic $\mathrm{H}_{2}$ production performance $\uparrow$}

\author{
Guangzhi Dong, (D) ab Yun Wen, ${ }^{2}$ Huiqing Fan, (D) *a Chao Wang, (D) ac \\ Zhenxiang Cheng, (D) ${ }^{\mathrm{b}}$ Mingchang Zhang, ${ }^{a}$ Jiangwei $\mathrm{Ma}^{\mathrm{a}}$ and Shujun Zhang $\mathbb{D}^{\mathrm{b}}$
}

\begin{abstract}
Graphitic carbon nitride $\left(\mathrm{g}-\mathrm{C}_{3} \mathrm{~N}_{4}, \mathrm{CN}\right)$ with nitrogen vacancies was synthesized by a controlled thermal etching method in a semi-closed air-conditioning system. The defect-modified $\mathrm{g}-\mathrm{C}_{3} \mathrm{~N}_{4}$ shows an excellent photocatalytic performance demonstrated by water splitting under visible light irradiation. With proper heat-treatment durations such as $2 \mathrm{~h}(\mathrm{CN} 2)$ and $4 \mathrm{~h}(\mathrm{CN} 4)$ at $550{ }^{\circ} \mathrm{C}$, the hydrogen production rates significantly increase to $100 \mu \mathrm{mol} \mathrm{h}-1$ and $72 \mu \mathrm{mol} \mathrm{h} \mathrm{h}^{-1}$, which are 11 times and 8 times the rate of the pristine $\mathrm{CN}\left(8.8 \mu \mathrm{mol} \mathrm{h}{ }^{-1}\right)$ respectively. The excellent hydrogen production performance of nitrogen defect modified CN2 is due to the synergy effect of the decreased band gap, enlarged specific surface area and increased separation/migration efficiency of photoinduced charge carriers. This simple defect engineering method provides a good paradigm to improve the photocatalytic performance by tailoring the electronic and physical structures of $\mathrm{g}-\mathrm{C}_{3} \mathrm{~N}_{4}$.
\end{abstract}

\section{Introduction}

Solar energy is one of the promising renewable resources to meet sustainable energy development. The utilization of solar energy has aroused extensive attention over decades. ${ }^{1,2}$ Hydrogen $\left(\mathrm{H}_{2}\right)$ evolution by splitting water under solar light has been regarded as an efficient strategy to utilize the solar energy. ${ }^{3-5}$ Therefore, developing proper photocatalysts has been actively studied in recent years. ${ }^{6-8}$ Graphitic carbon nitride ( $\mathrm{g}$ $\mathrm{C}_{3} \mathrm{~N}_{4}$ ), as a new layered compound, is found to possess many merits, including appropriate band structure, high thermal and chemical stability and visible-light activity. ${ }^{2,9-11}$ Nonetheless, the shortcomings, such as poor quantum conversion efficiency, high recombination of photogenerated carriers and small specific surface area, greatly limit the application of bulky g$\mathrm{C}_{3} \mathrm{~N}_{4}$ in water splitting. ${ }^{12,13}$ Therefore, numerous approaches, ${ }^{14}$ including exfoliation ${ }^{15-17}$ structural modification ${ }^{18-20}$ and nano/ microstructure design ${ }^{21-23}$ have been developed to enhance the photoactivity of $\mathrm{g}-\mathrm{C}_{3} \mathrm{~N}_{4}$. All these above-mentioned methods tune the band structure and accelerate the migration and separation of photoinduced charge carriers, however, they

${ }^{a}$ State Key Laboratory of Solidification Processing, School of Materials Science and Engineering, Northwestern Polytechnical University, Xi'an, 710072, PR China. E-mail: hqfan@mwpu.edu.cn

${ }^{b}$ Institute for Superconducting and Electronic Materials, Australia Institute of Innovative Materials, University of Wollongong, Wollongong, 2522, Australia

'Department of Chemical Engineering, University College London, Torrington Place, London WC1E 7JE, UK

$\dagger$ Electronic supplementary information (ESI) available. See DOI: 10.1039/d0ra01425g suffer from complicate synthesis or limited light harvesting. Thus, seeking simple way to tailor the electronic structure and enlarge visible light harvesting range is desired for $\mathrm{g}-\mathrm{C}_{3} \mathrm{~N}_{4}$.

Very recently, atomic level modification has attracted substantial interests owing to its good effect in photocatalysis. ${ }^{24}$ For instance, substitution atoms (heteroatoms: $\mathrm{O},{ }^{25} \mathrm{P}^{4}{ }^{4} \mathrm{~N}^{26}$ ) could either provide extra delocalized electrons or construct internal electric field to accelerate the separation of charge carries. In addition, interstitial atoms ${ }^{27}$ as well as carbon/ nitrogen defects ${ }^{28,29}$ for two-dimension (2D) layered $\mathrm{g}-\mathrm{C}_{3} \mathrm{~N}_{4}$ play important role in promoting the performance in photocatalysis due to the hindrance of the recombination of photoinduced carries and extending the visible-light adsorption. Especially, among these works, nitrogen vacancies have many unique merits in visible-light harvesting, ${ }^{28,30}$ which act as a trap to capture the carries and introducing defect energy level. Accordingly, efforts have been made to effectively facilitate the separation of charge carriers through introducing point defects. For instance, it was reported that directly heating precursor (urea, melamine) and alkali can dramatically enlarge the range of light harvesting by decreasing the conduction band (CB) minimum. ${ }^{31}$ Post heating in ammonia/hydrogen or in other inert atmosphere is an alternative way to realize the introduction of defects with the intent of promoting red-shift of light absorption. ${ }^{28,32,33}$ One of the most important tasks is to explore an environmental friendly and low-cost way to enhance the photoreactivity through defects controlling, the behind mechanism of the introduction of defects needs to be established to in-depth understand the process of defects modification. 
In this work, a simple method was developed to introduce nitrogen defects into $\mathrm{g}-\mathrm{C}_{3} \mathrm{~N}_{4}$ by post-heating raw carbon nitride in a semi-closed system (only air out) filled with air. This aircondition method makes the thermal-treatment process safer, cheaper and more convenient than the reducing gas treatment. With increasing the annealing time, the optical absorption range of the thermal treated polymeric carbon nitride (defects modified g- $\mathrm{C}_{3} \mathrm{~N}_{4}$ ) exhibits a slight red-shift at first, followed by a remarkable blue-shift. Combined with the elemental analysis (EA) and X-ray photoelectron spectroscopy (XPS), it suggests that the $\mathrm{N}$ vacancies have an enormous effect on suppressing the recombination of charge carriers. The modified electronic structure and enlarged specific surface area play an important role in improving photocatalytic hydrogen evolution. This method may provide a direct way to study thermal treatment and promote the application of defect engineering in other semiconductors.

\section{Experimental}

\subsection{Synthesis of $\mathrm{g}-\mathrm{C}_{3} \mathrm{~N}_{4}$}

Pristine graphitic carbon nitride $\left(\mathrm{g}-\mathrm{C}_{3} \mathrm{~N}_{4}\right)$ was synthesized by thermal treatment of dicyandiamide (DCDA) at $550{ }^{\circ} \mathrm{C}$ for $4 \mathrm{~h}$ with a ramp rate of $5{ }^{\circ} \mathrm{C} \mathrm{min}{ }^{-1}$, which is similar to our previous works. ${ }^{16,34,35}$ The obtained bulk carbon nitride was then milled into powders in an agate mortar.

\subsection{Synthesis of defects modified $\mathrm{g}-\mathrm{C}_{3} \mathrm{~N}_{4}$}

The defects modified g- $\mathrm{C}_{3} \mathrm{~N}_{4}$ was prepared by post-heating raw $\mathrm{g}-\mathrm{C}_{3} \mathrm{~N}_{4}$ powders in a semi-closed tube furnace filled with air. $1.5 \mathrm{~g}$ carbon nitride powder was put in a porcelain boat and placed in a tube furnace, and one end of the tube was sealed and the other was connected with a hose in a glass of deionized water. Subsequently, the tube furnace was heated to $550{ }^{\circ} \mathrm{C}$ for $x$ $=2$ or $4 \mathrm{~h}$ (characteristic times) with a ramp rate of $5^{\circ} \mathrm{C} \mathrm{min}^{-1}$. The obtained samples were denoted as $\mathrm{CN} x$ ( $x$ means hour duration of thermal treatment).

\subsection{Materials characterizations}

The phase structure was investigated by X-ray diffraction diffractometer (XRD; X'pert, Philips Eindhoven, The Netherlands) with $\mathrm{Cu} \mathrm{K}$ irradiation. Fourier transform infrared spectra were performed on a spectrometer (FT-IR; TENSOR27, Bruker, Billerica, MA, USA). The chemical composition was studied by X-ray photoelectron spectroscopy (XPS; ESCALAB220i-XL, Thermo Scientific, Waltham, MA, USA) using $\mathrm{Al} \mathrm{K}_{\alpha}$ radiation as the excitation source. The optical properties were investigated by ultraviolet-visible spectrophotometer (UVvis; UV-3600, Shimadzu, Tokyo, Japan). Photoluminescence spectra were recorded on a fluorescence spectrophotometer (PL; FLSP-920, Edinburgh Instruments, Edinburg, UK) with an excitation wavelength of $337 \mathrm{~nm}$. The morphology of the samples was examined by scanning electron microscope (FESEM; JSM-6701F, JEOL, Tokyo, Japan) and transmission electron microscope (JEM-3010, JEOL, Tokyo, Japan). Nitrogen adsorption/desorption isotherms were performed using surface area analyzer (V-sorb 2800P, Gold APP Instruments, Beijing, China). Photoelectrochemical properties were characterized by electrochemical workstation (CHI 660E, CH Instruments, Shanghai, China) in a standard three-electrode cell with $0.5 \mathrm{M}$ $\mathrm{Na}_{2} \mathrm{SO}_{4}$ solution.

\subsection{Photocatalytic performance measurement}

The photocatalytic performance is evaluated by hydrogen evolution from water splitting under visible light irradiation, which were carried out in a quartz reaction vessel connected to a glass gas-circulation system. $50 \mathrm{mg}$ photocatalysts was dispersed in $10 \mathrm{wt} \%$ triethanolamine solution. After vigorously stirring for $30 \mathrm{~min}, 3 \mathrm{wt} \% \mathrm{Pt}$ was deposited on the surface of $\mathrm{C}_{3} \mathrm{~N}_{4}$ as co-catalyst using $\mathrm{H}_{2} \mathrm{PtCl}_{6}$ as precursor though in situ photodeposition. Prior to reaction, the system was vacuumed several times to remove air completely. A $300 \mathrm{~W}$ xenon lamp (MAX-302, Asahi Spectra, Torrance, CA, USA) with a cut-off filter $(\lambda>400 \mathrm{~nm})$ was chosen as the light source, and the system was maintained at $10{ }^{\circ} \mathrm{C}$. The rate of hydrogen evolution was determined by a gas chromatography.

\section{Results and discussion}

\subsection{Phase structure and chemical composition}

The phase structure of the as-prepared samples was investigated by X-ray diffraction, as shown in Fig. 1a. The XRD patterns exhibit two characteristic peaks centered at $13.1^{\circ}$ and around $27.5^{\circ}$, which are ascribed to the in-planar repeat motif and the interlayer periodic stacking of $\mathrm{g}-\mathrm{C}_{3} \mathrm{~N}_{4}$ sheets, respectively. ${ }^{36}$ Additionally, the sharp peak at $27.5^{\circ}$ assigned to the (002) crystal planes shifts to higher $2 \theta$ angles with increasing the treatment time, implying a gradually reduced crystal plane distance originated from the thermal treatment. ${ }^{34,37}$

Fourier transform infrared spectra (FT-IR) were carried out to illustrate the phase structure of the samples (Fig. 1b). All the samples show a sharp peak at $812 \mathrm{~cm}^{-1}$ assigned to the bending
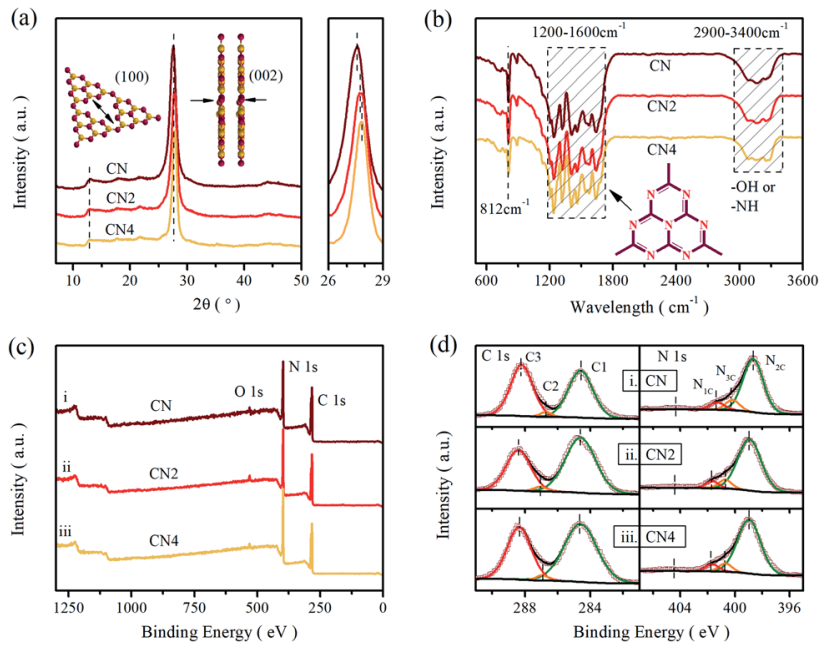

Fig. 1 (a) XRD patterns, (b) FT-IR spectra, (c) XPS survey spectra, and (d) high resolution $\mathrm{C}$ 1s and $\mathrm{N}$ 1s XPS spectra of $\mathrm{CN}, \mathrm{CN} 2$, and $\mathrm{CN} 4$. 

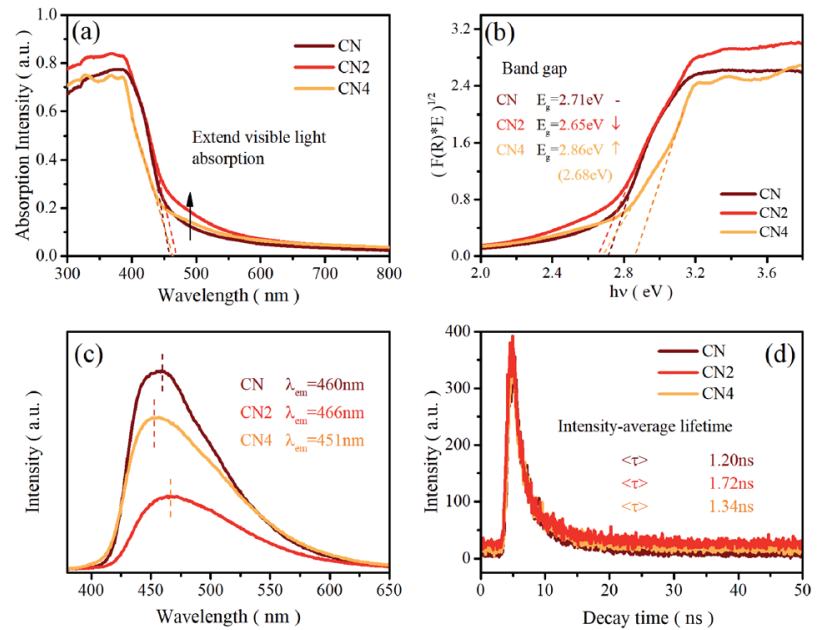

Fig. 2 (a) UV-vis diffuse reflectance spectra, (b) $(F(R) \times E)^{1 / 2}$ versus $h \nu$ plot, (c) PL spectra, and (d) time-resolved fluorescence decay spectra of $\mathrm{CN}, \mathrm{CN} 2$ and $\mathrm{CN} 4$.

mode of tri-s-triazine units, ${ }^{38}$ and a band in the range of 1200 $1600 \mathrm{~cm}^{-1}$ relates to the stretching vibration mode of heptazine rings. ${ }^{36,39}$ Moreover, the fingerprint band in $2900-3400 \mathrm{~cm}^{-1}$ can be attributed to the absorbed $\mathrm{H}_{2} \mathrm{O}$ and terminal amino group $\left(-\mathrm{NH}_{x}\right) \cdot{ }^{\mathbf{4 0 , 4 1}}$ These results further confirmed the basic structure of carbon nitride was maintained during the thermal treatment, even though some minor changes can be observed. The peak at $812 \mathrm{~cm}^{-1}$ and the broad band over $2900-3400 \mathrm{~cm}^{-1}$ are both weakened as the thermal treatment time increased, implying that the decrease of the amino group and the decomposition of the $\mathrm{CN}$ heterocycles. Besides, the peaks of stretching vibration mode for tri-s-triazine rings are much sharper than raw $\mathrm{g}-\mathrm{C}_{3} \mathrm{~N}_{4}$, indicating the formation of thin layered structure. ${ }^{16}$ These changes illustrate that the thermal treatment can reduce the terminal amino and produce thin layered structure.

To further confirm the reduction of the amino group, the $\mathrm{X}$ ray photoelectron spectroscopy test and element analysis (EA) were performed, as shown in Fig. 1c and d. It is clear that the XPS shows two sharp peaks (assigned to $\mathrm{C} 1 \mathrm{~s}$ and $\mathrm{N} 1 \mathrm{~s}$ ) and a small peak (related to $\mathrm{O} 1 \mathrm{~s}$ ). In Fig. 1d, the enlarged XPS spectra shows that the $\mathrm{C} 1 \mathrm{~s}$ peak is deconvoluted into three peaks centered at $284.6 \mathrm{eV}, 287.11 \mathrm{eV}$ and $288.4 \mathrm{eV}$ by Gaussian curve fitting, which can be attributed to foreign graphitic carbon, $\mathrm{sp}^{2}$-hybridized carbon connected to primary or secondary amino group and $\mathrm{sp}^{2}$ hybridized carbon in the heteroaromatic ring, respectively. ${ }^{\mathbf{4 2 - 4 4}}$ Similarly, three peaks deconvoluted from N 1s spectra located at $398.96 \mathrm{eV}, 400.68 \mathrm{eV}$ and $401.66 \mathrm{eV}$ are assigned to $\mathrm{sp}^{2}$-hybridized nitrogen in triazine rings $\left(\mathrm{N}_{2 \mathrm{C}} ; \mathrm{C}-\mathrm{N}=\mathrm{C}\right)$, tertiary nitrogen $\left(\mathrm{N}_{3 \mathrm{C}} ; \mathrm{N}-(\mathrm{C})_{3}\right)$ and amino group $\left(\mathrm{N}_{1 \mathrm{C}} ;-\mathrm{NH}_{x}\right) .^{\mathbf{1 8 , 3 1 , 4 5}}$ The area ratios of the obtained peaks are listed in the Table $\mathrm{S} 1, \dagger$ exhibiting the content variation of nitrogen in different status. The ratios of the $\mathrm{sp}^{2}$-hybridized nitrogen to the tertiary nitrogen are 6.61, 5.66 and 6.63 , respectively. Meanwhile, from the high resolution of $\mathrm{O} 1 \mathrm{~s}$ spectra (Fig. S1 $\dagger$ ), all the samples exhibit two peaks centered at $532.0 \mathrm{eV}$ and $533.4 \mathrm{eV}$, which originate from the absorbed $\mathrm{H}_{2} \mathrm{O}$ and $\mathrm{O}=\mathrm{C}$, respectively. ${ }^{46}$ The result of the element analysis is a convincing proof of the existence of nitrogen defects. The mass ratios of $\mathrm{N}: \mathrm{C}$ for the samples from element analysis results are 1.767, 1.711 and 1.710 (Table $S 2 \dagger$ ), respectively, suggesting that the decrease of nitrogen content after heat treatment. Furthermore, the variation of the surface $\mathrm{N}$ : $\mathrm{C}$ ratios from XPS results are $2.327,2.288$ and 2.252 , respectively. The decreasing $\mathrm{N}: \mathrm{C}$ ratios also indicating that the existence of nitrogen vacancies after the post-thermal treatment. Combined with XPS result from $\mathrm{CN}$ to $\mathrm{CN} 2$, it is analyzed that the missing $\mathrm{N}$ atoms mainly originate from amino group and some two-coordinated nitrogen. There is no obvious change in mass ratio and distribution of amino from $\mathrm{CN} 2$ to $\mathrm{CN} 4$, which is mainly attributed to the reduction of $\mathrm{C}$ and $\mathrm{N}$ by etching the heteroaromatic rings.

\subsection{Optical properties}

Ultraviolet-visible light absorption spectra are shown in Fig. 2a and b. The typical absorption spectra of semiconductor can be observed with the absorption edge located at $460 \mathrm{~nm}$ for $\mathrm{CN}, 466 \mathrm{~nm}$ for $\mathrm{CN} 2$ and $462 \mathrm{~nm}$ for $\mathrm{CN} 4$, which are in accordance with the red-shift from $\mathrm{CN}$ to $\mathrm{CN} 2$ and blueshift from $\mathrm{CN} 2$ to $\mathrm{CN} 4$. The corresponding band gaps are $2.71 \mathrm{eV}$ for $\mathrm{CN}, 2.65 \mathrm{eV}$ for $\mathrm{CN} 2$ and $2.86 \mathrm{eV}$ for $\mathrm{CN} 4$ (the gap between defects energy level and valence band for CN4 is 2.68 $\mathrm{eV}$ ). Combined with the valence band spectra, the schematic band structure was plotted and shown in Fig. S2. $\dagger$ The conduction bands are located at $-1.00 \mathrm{eV},-0.83 \mathrm{eV}$ and $-0.95 \mathrm{eV}$ for $\mathrm{CN}, \mathrm{CN} 2$ and $\mathrm{CN} 4$. Both conduction band and valence band first shift down for CN2 mainly due to the effect of the nitrogen defects, while they shift up from CN2 to CN4 as a result of the synergetic effects of quantum confinement effect and nitrogen defects. ${ }^{33}$

Photoluminescence spectra were employed to investigate the radiative recombination efficiency of the photogenerated charge carriers. As can be seen in Fig. 2c, the peak intensity of the defects-modified $\mathrm{g}-\mathrm{C}_{3} \mathrm{~N}_{4}$ is obviously quenched, illustrating that the nitrogen defects play an important role in improving charge carrier's separation efficiency. The decrease of peak intensity from $\mathrm{CN}$ to $\mathrm{CN} 2$ may be mainly due to the new defectsinduced surface states to form the carrier traps, which can capture the carriers and inhibit the recombination of carriers. Nevertheless, the intensity of CN4 increases from CN2 even if it is still weaker than pristine $\mathrm{CN}$. This result suggests that thermal treatment would destroy the tri-s-triazine rings leading to reduced charge carrier's separation efficiency, which is consistent with the analysis result from the EA and XPS spectra. The emission peaks of the samples, regarded as the band-toband recombination of holes and electrons, ${ }^{28,47}$ are located at $459 \mathrm{~nm}$ (2.70 eV), $466 \mathrm{~nm}$ (2.66 eV) and $451 \mathrm{~nm}$ (2.75 eV), which is in accordance with the variation trend of the band gap. The analysis of PL spectra shows that the defect state structure is benefit to the separation of carriers, resulting in low recombination efficiency of photo excited electron hole pairs and eventually higher photocatalytic activity.

Time-resolved photoluminescence spectra (TRPL) were also performed on a fluorescence spectrophotometer, which exhibit 
an exponential decay of carrier lifetime, as shown in Fig. 2d. The spectra were fitted using a two-exponential decay function with short and long lifetimes $\tau_{1}$ and $\tau_{2}$, corresponding to the trapping of electrons by the defects at short and long distances, respectively. The components of the lifetime are given in Table S3. $\dagger$ The average lifetime $(\langle\tau>)$ can be calculated as $1.20 \mathrm{~ns}, 1.72 \mathrm{~ns}$, and $1.34 \mathrm{~ns}$, for $\mathrm{CN}, \mathrm{CN} 2$ and $\mathrm{CN} 4$. The average charge lifetimes of defects modified $\mathrm{g}-\mathrm{C}_{3} \mathrm{~N}_{4}$ are longer than pristine carbon nitride clearly suggesting that the nitrogen defects prolong the charge lifetimes of the photocatalysts. At the same time, the charge lifetime of $\mathrm{CN} 4$ decreases in comparison to $\mathrm{CN} 2$, which is possibly due to the charge localization. The nitrogen defects promote the charge carriers migration from the inner to the surface to participate in the water-splitting reactions.

\subsection{Morphology and microstructure evolution}

The sample was prepared by directly heating raw graphitic carbon nitride in a semi-sealed system for different times at $550{ }^{\circ} \mathrm{C}$, and the yield of as-prepared samples decreased as the treat time increased. The comparison of volume and color for $300 \mathrm{mg}$ of CN, CN2, and CN4 is shown in Fig. S3. $\dagger$ The colors of the as-prepared samples show an obvious change. Contrast to raw materials, the color of the treated CN2 shows darker color. Moreover, the TEM images and SEM images are the most intuitionistic evidence to illustrate the changes of morphology. It's obvious that the thermal treatment had a significant influence on the defects modified $\mathrm{g}-\mathrm{C}_{3} \mathrm{~N}_{4}$ (Fig. 3). As can be seen, the pristine $\mathrm{g}-\mathrm{C}_{3} \mathrm{~N}_{4}$ consist of bulky aggregations with a relatively smooth surface, and the rough lateral edge illustrates that they are formed by multilayer stacking. Meanwhile, thinner layered structure was observed in defects modified $\mathrm{g}-\mathrm{C}_{3} \mathrm{~N}_{4}$. With the further increase of treat time, different from the $\mathrm{CN} 2$, the edge of the CN4 is curling and wrinkled, which suggests further reduced thickness. SEM images of Fig. S4† shows that the particles of the pristine carbon nitride possess a much smoother surface, while the particles of the CN2 keep this feature and the CN4 possesses a thinner layered structure with clearly visible pores. Atomic force microscopy was observed on
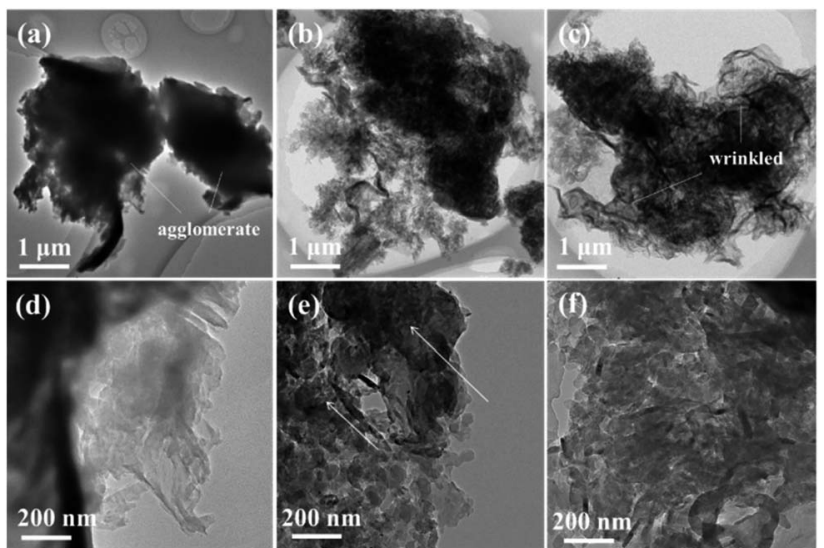

Fig. $3(a-c)$ TEM, and $(d-f)$ HRTEM images of ( $a$ and $d) C N$, (b and $e$ ) CN2 and (c and f) CN4.
CN4 as the representative to further confirm that the nanosheets were obtained (Fig. S5†). Result shows that thickness of the sheets is around $5.6 \mathrm{~nm}$, implying the formation of thin layered structure.

In order to illustrate the evolution of layer thickness with heat treatment, dispersing stability experiment was carried out (Fig. S6 $\dagger$ ). It is worth to note that the thermal-treated samples were much more stable in suspension after natural sedimentation for 20 days judging by the light transmittance. After natural sedimentation for 15 days, the obtained CN4 is more stable than $\mathrm{CN} 2$ and $\mathrm{CN}$ which might be owing to the larger specific surface area originated from lower thickness and porous structure. Besides that, the tail gas solution is alkaline which suggests the post-treatment can reduce lattice $\mathrm{N}$ into ammonia (Fig. S7†). Obviously, because no adventitious hydrogen atoms have been provided, the $\mathrm{H}$ atoms in ammonia can be determined mainly from the primary or secondary amino group $\left(\mathrm{N}_{1 \mathrm{C}}\right)$. This result is in accordance with the decrease of amino from the XPS results and the others' works. ${ }^{48-50}$ With further heat treatment, the tri-s-triazine units are destroyed due to the collapse of incomplete $\mathrm{CN}$ heterocycles (Fig. 4). The gases release during the treatment and exfoliate the agglomerates into thin layers. Correspondingly, the surface area was determined by $\mathrm{N}_{2}$ adsorption-desorption analysis (Fig. S8 $\dagger$ ). After post-heating, the specific surface area of the samples was gradually increased from $4.05 \mathrm{~m}^{2} \mathrm{~g}^{-1}$ of $\mathrm{CN}$ to $12.79 \mathrm{~m}^{2} \mathrm{~g}^{-1}$ of $\mathrm{CN} 2$ and $21.26 \mathrm{~m}^{2} \mathrm{~g}^{-1}$ of $\mathrm{CN} 4$, the corresponding pore size distribution curves calculated by the adsorption branches are provided. As we can see, there is a little bit difference of the pore size distribution between the defects modified $\mathrm{g}-\mathrm{C}_{3} \mathrm{~N}_{4}$ and pristine $\mathrm{g}-\mathrm{C}_{3} \mathrm{~N}_{4}$. The minimum diameter of the pores has reduced to $2 \mathrm{~nm}$ of CN4 and $5 \mathrm{~nm}$ of CN2 from around $15 \mathrm{~nm}$ of the pristine $\mathrm{CN}$. The pore distribution curve of $\mathrm{CN} 4$ has an obvious peak at the range of 2-4 nm and 6-50 nm, the former emerges from the destruction of the heptazine ring and the breaking of the ammonia bubbles, and the latter results from the decomposition of oligomer fragments and the collapse of the wall of the primary pores. From the above results, it can be found that this post-treating process is a dynamic process. During this process, the nitrogen defects were introduced into the texture through releasing ammonia and result in incomplete rings at first, and then the incomplete units were more easily destroyed during further thermal treatment.

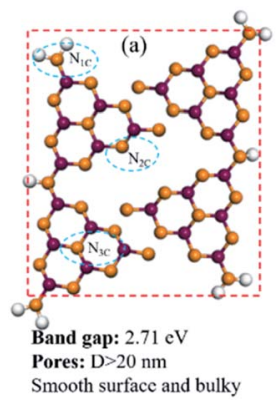

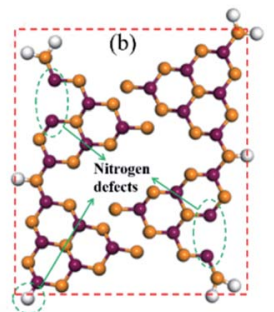

Band gap: $2.65 \mathrm{cV}$ Pores: $\mathrm{D}>10 \mathrm{~nm}$ Porous structure

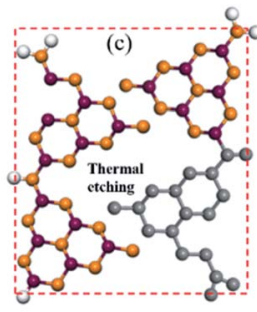

Band gap: $2.86 \mathrm{cV}(2.68 \mathrm{cV})$ Pores: $\mathrm{D}>2 \mathrm{~nm}$ Porous and thin layered structure
Fig. 4 Structure model of (a) CN, (b) CN2, and (c) CN4. 


\subsection{Electronic properties}

Electron paramagnetic resonance (EPR) measurements were performed at $77 \mathrm{~K}$ to investigate the structural defects in the modulated graphitic carbon nitride. All samples show one single Lorentzian line, which is related to lone pair electrons on $\mathrm{sp}^{2}$-carbon within the heptazine rings. ${ }^{33,51}$ As shown in Fig. 5a, the EPR signal intensity of these samples displays a trend of first enhancement and then weakening with the increasing of treatment time. Nitrogen vacancies would introduce more lone pair electrons and result in stronger EPR intensity. Meanwhile, the broken of heptazine rings would reduce the concentration of delocalized electrons and exhibit reduced EPR intensity in comparison with $\mathrm{CN} 2$ consequently. Moreover, the defects modulated $\mathrm{g}-\mathrm{C}_{3} \mathrm{~N}_{4}$ exhibits a stronger intensity than $\mathrm{CN}$, clearly implying the increase of delocalized electrons. It is noteworthy that this trend is in good consistent with previous analysis.

To further investigate the migration and separation efficiency of charge carriers, the transient photocurrent response and electrochemical impedance spectroscopy (EIS) tests were carried out (Fig. 5b-d). Compared with the raw $\mathrm{g}-\mathrm{C}_{3} \mathrm{~N}_{4}$, the treated $\mathrm{g}-\mathrm{C}_{3} \mathrm{~N}_{4}$ shows remarkably enhanced photocurrent density, implying the outstanding photoelectric response under visible light illumination and more efficient separation of photoinduced electron-hole pairs. ${ }^{52}$ For the EIS Nyquist plots of Fig. 5c, the smaller arc radiuses of the CN2 and CN4 suggest a smaller charge migration resistance. To better simulate the change of the charge transfer resistance, the EIS spectra of CN2 were also performed under visible-light irradiation and after adding $10 \%$ (mass ratio) triethanolamine (TEOA) in the electrolyte (0.5 mol L${ }^{-1} \mathrm{Na}_{2} \mathrm{SO}_{4}$ solution), as shown in Fig. $5 \mathrm{~d}$. Under the illumination of visible light, the resistance reduces clearly due to the photovoltage reduces the energy barriers of charge migration. Moreover, it is very clear that the impedance attains a minimum with the coexistence of light and triethanolamine, demonstrating that the triethanolamine as a scavenger can trap the holes to free the photoinduced electrons.
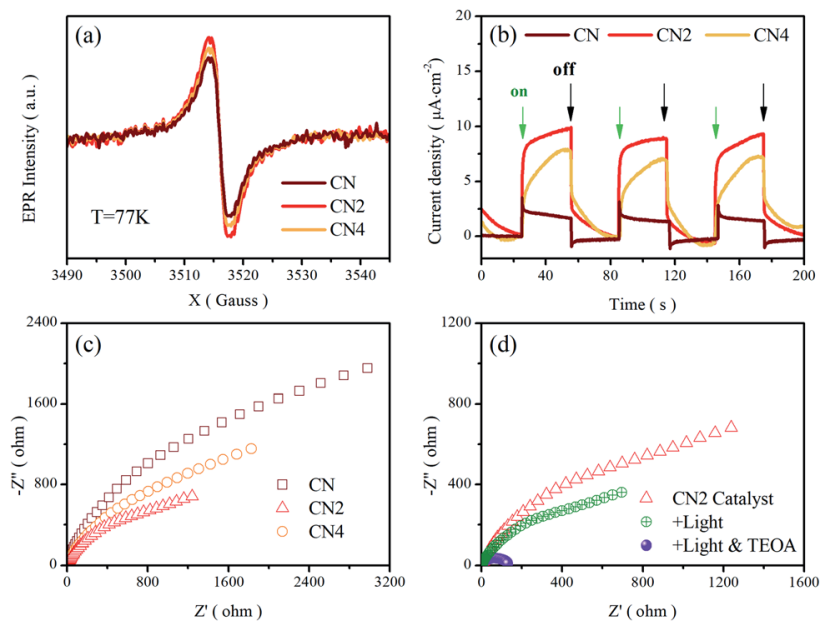

Fig. 5 (a) EPR spectra, and (b) transient photocurrent response, and (c) Nyquist plots of CN, CN2 and CN4. (d) Nyquist plots of CN2 at different condition

\subsection{Photocatalytic performance}

Photocatalytic performance was tested by water splitting under visible light irradiation using $3 \mathrm{wt} \% \mathrm{Pt}$ as co-catalyst and 10 vol\% triethanolamine as scavenger. Photocatalytic hydrogen evolution rate of catalysts is shown in Fig. 6a. Obviously, CN2 and $\mathrm{CN} 4$ show remarkable enhancement in $\mathrm{H}_{2}$ yields, while the $\mathrm{CN} 2$ produces a total amount of $401.57 \mu \mathrm{mol}\left(100.53 \mu \mathrm{mol} \mathrm{h}{ }^{-1}\right)$ and CN4 produce $284.04 \mu \mathrm{mol}\left(71.88 \mu \mathrm{mol} \mathrm{h}^{-1}\right)$ after 4 hours of visible light irradiation. The superior photocatalytic performance of $\mathrm{CN} x$ indicates that the thermal treatment is highly beneficial to optimize the optical and electronic properties. Moreover, the apparent quantum yield (AQY) values are carried out by splitting water using monochromatic light illuminating. As shown in Fig. S9, $\uparrow$ the AQY values of $\mathrm{CN} 2$ reached $10.38 \%$ at $420 \mathrm{~nm}$ and $0.53 \%$ at $550 \mathrm{~nm}$, which is in accordance with the trend of the light harvesting result. At the same time, the CN2 exhibits higher photocatalytic activity than the CN4, which is most probably due to the synergistic effects of optical performance and the separation efficiency of photoinduced charge carriers. Besides, compared with the pristine $\mathrm{CN}$, larger specific surface area can provide more reactive sites and the pore structure reduces the diffusion length of carriers from interior to the outer surface. In addition, stability is another key factor to the commercial application of the photocatalyst. The cycling test was carried out under the same condition after storing in the solution for 20 days to evaluate the stability of $\mathrm{CN} 2$ photocatalyst. As displays in Fig. $6 \mathrm{~b}$, the $\mathrm{H}_{2}$ production rate didn't exhibit significant decrease even the experiment was repeated after three weeks, which confirm the enhanced stability of nitrogen vacancies modified $\mathrm{g}-\mathrm{C}_{3} \mathrm{~N}_{4}$.

Based on the above results, we could conclude that the nitrogen defects play a key role in enhancing the photocatalytic performance. It has been widely accepted that excellent photocatalytic performance is strongly relying on three crucial factors: (1) hindered radiative recombination of photoinduced charge carriers (2) increased specific surface area (3) tuned band structure and enlarged visible light harvesting capacity. During thermal etching in a semi-closed system, nitrogen defects was produced by releasing ammonia as a result of thermal treatment, and then, further treatment leads to the destruction of tri-s-triazine and thin layered structure. In this evolution process, the introduction of nitrogen defects and the breakage caused by thermal etching will modify the electronic
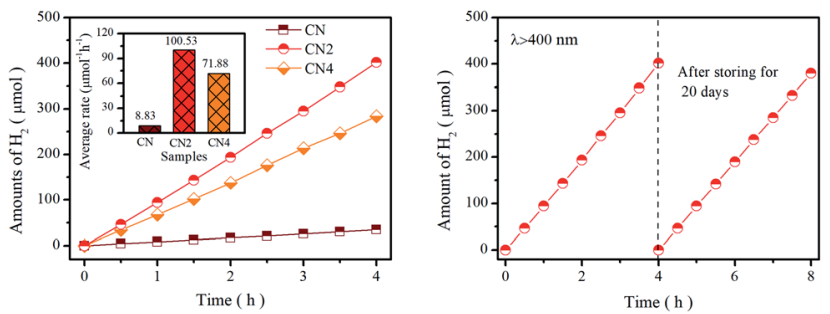

Fig. 6 (a) Amount of $\mathrm{H}_{2}$ generation of $\mathrm{CN}, \mathrm{CN} 2$, and $\mathrm{CN} 4$ under the irradiation of visible light $(\lambda>400 \mathrm{~nm}),\left(\right.$ b) comparison of the $\mathrm{H}_{2}$ generation rate between the first cycle and after storing for 20 days for CN2. 
structure, expand the range of light absorption and suppress the recombination of carriers. It should be noted that the introduction of defects can also damage the stable structure, which directly leads to the broken of the tri-s-triazine after the thermal treatment. To sum up, the nitrogen defects can be introduced into $\mathrm{g}-\mathrm{C}_{3} \mathrm{~N}_{4}$ by proper duration of thermaltreatment to reduce the energy barrier of charge migration and prolong lifetime of photoinduced charge carriers, which all contribute to the improvement of photocatalytic performance of the defect modified $\mathrm{g}-\mathrm{C}_{3} \mathrm{~N}_{4}$.

\section{Conclusions}

In summary, an effective thermal-treatment method in a semiclosed system was developed for the preparation of defects modified g- $\mathrm{C}_{3} \mathrm{~N}_{4}$. Nitrogen defects were controllably introduced into the framework of $\mathrm{g}-\mathrm{C}_{3} \mathrm{~N}_{4}$ and the porous thin-layered structure was formed by adjusting the thermal-treated duration. Compared with $\mathrm{CN}$ (pristine $\mathrm{g}-\mathrm{C}_{3} \mathrm{~N}_{4}$ ), the hydrogen evolution rate of $\mathrm{CN} 2\left(\mathrm{~g}-\mathrm{C}_{3} \mathrm{~N}_{4}\right.$ treated for $2 \mathrm{~h}$ ) has been significantly improved to $100 \mu \mathrm{mol} \mathrm{h}^{-1}$ from $8 \mu \mathrm{mol} \mathrm{h}^{-1}$ of $\mathrm{CN}$, and then slightly decrease to72 $\mu \mathrm{mol} \mathrm{h}^{-1}$ for CN4 when the heat treatment duration was prolonged to $4 \mathrm{~h}$. The underlying origins associated with the fluctuation of hydrogen production performance include the heat treatment induced modification of bandgap, structure, specific surface area and photogenerated carrier lifetime, as well as their synergistic effects. During this process, short-term heat treatment (CN2) narrows the band gap $(\sim 2.65 \mathrm{eV})$ by introducing defect states resulted in enhanced visible light responses, while excessive treatment duration (CN4) would severely destruct the framework of graphitic carbon nitride. In addition, the reduction of charge transfer barrier and the longer of photo-induced carrier lifetime are also critical for hydrogen production performance. The method developed in this work demonstrates an efficient and simple process to the predictable modification of electronic structure and the contrivable regulation of hydrogen production performance in related material systems.

\section{Conflicts of interest}

There are no conflicts to declare.

\section{Acknowledgements}

This work has been supported by the National Natural Science Foundation (51672220, 51902258), the Fundamental Research Funds for the Central Universities of NPU (3102019GHXM002), the State Key Laboratory of Solidification Processing Project (2019-TZ-04) of China, the China Postdoctoral Science Foundation (2019M653729), the Shaanxi Province Postdoctoral Science Foundation (2017BSHEDZZ07), and the Natural Science Foundation of Shaanxi Province (2019JQ-621). We would also like to thank the Analytical \& Testing Center of Northwestern Polytechnical University.

\section{References}

1 A. Kudo and Y. Miseki, Chem. Soc. Rev., 2009, 38, 253-278.

2 M. Nasir, G. Yang, I. Ayub, S. Wang, L. Wang, X. Wang, W. Yan, S. Peng and S. Ramakarishna, Appl. Catal., B, 2019, 257, 117855.

3 J. Ran, J. Zhang, J. Yu, M. Jaroniec and S. Qiao, Chem. Soc. Rev., 2014, 43, 7787-7812.

4 J. Ran, T. Ma, G. Gao, X. Du and S. Qiao, Energy Environ. Sci., 2015, 8, 3708-3717.

5 S. Cao and J. Yu, J. Phys. Chem. Lett., 2017, 5, 2101-2107.

6 H. Shi, G. Chen, C. Zhang and Z. Zou, ACS Catal., 2014, 4, 3637-3643.

7 P. Song, S. Liang, J. Cui, D. Ren, R. Duan, Q. Yang and S. Sun, Catal. Sci. Technol., 2019, 9, 5150-5159.

8 S. Cao, C. Wang, G. Wang, Y. Chen, X. Lv and W. Fu, RSC Adv., 2020, 10, 5930-5937.

9 X. Wang, K. Maeda, A. Thomas, K. Takanabe, G. Xin, J. Carlsson, K. Domen and M. Antonietti, Nat. Mater., 2008, 8, 76-80.

10 X. Liu, F. Pang, M. He and J. Ge, Nano Res., 2017, 10, 3638-3647. 11 X. Bi, S. Yu, E. Liu, X. Yin, Y. Zhao and W. Xiong, RSC Adv., 2020, 10, 524-532.

12 F. Dong, Z. Zhao, T. Xiong, Z. Ni, W. Zhang, Y. Sun and W. Ho, ACS Appl. Mater. Interfaces, 2013, 5, 11392-11401.

13 W. Iqbal, C. Dong, M. Xing, X. Tan and J. Zhang, Catal. Sci. Technol., 2017, 7, 1726-1734.

14 F. Kessler, Y. Zheng, D. Schwarz, C. Merschjann, W. Schnick, X. Wang and M. Bojdys, Nat. Rev. Mater., 2017, 2, 17030.

15 X. Dong and F. Chen, J. Mater. Chem. A, 2015, 3, 2364223652.

16 L. Ma, H. Fan, M. Li, H. Tian, J. Fang and G. Dong, J. Mater. Chem. A, 2015, 3, 2244-22412.

17 L. Fang, Y. Li, P. Liu, D. Wang, H. Zeng, X. Wang and H. Yang, ACS Sustainable Chem. Eng., 2017, 5, 2039-2043.

18 W. Che, W. Cheng, T. Yao, F. Tang, W. Liu, H. Su, Y. Huang, Q. Liu, J. Liu, F. Hu, Z. Pan and Z. Sun, J. Am. Chem. Soc., 2017, 139, 3021-3026.

19 Y. Yu, W. Yan, W. Gao, P. Li, X. Wang, S. Wu, W. Song and K. Ding, J. Mater. Chem. A, 2017, 5, 17199-17203.

20 Y. Zhou, L. Zhang, W. Huang, Q. Kong, X. Fan, M. Wang and J. Shi, Carbon, 2016, 99, 111-117.

21 Z. Tong, D. Yang, Y. Sun, Y. Nan and Z. Jiang, Small, 2016, 12, 4093-4101.

22 C. Liu, H. Huang, L. Ye, S. Yu, N. Tian, X. Du, T. Zhang and Y. Zhang, Nano Energy, 2017, 41, 738-748.

23 X. Li, B. Wang, X. Shu, D. Wang, G. Xu, X. Zhang, J. Lv and Y. Wu, RSC Adv., 2019, 9, 15900-15909.

24 A. D. Fortes, E. Suard and K. S. Knight, Science, 2011, 331, 742-746.

25 Y. Zeng, X. Liu, C. Liu, L. Wang, Y. Xia, S. Zhang, S. Luo and Y. Pei, Appl. Catal., B, 2018, 224, 1-9.

26 J. Fang, H. Fan, M. Li and C. Long, J. Mater. Chem. A, 2015, 3, 13819-13826.

27 T. Xiong, W. Cen, Y. Zhang and F. Dong, ACS Catal., 2016, 6, 2462-2472. 
28 P. Niu, L. Yin, Y. Yang, G. Liu and H. Cheng, Adv. Mater., 2014, 26, 8046-8052.

29 J. Di, J. Xia, X. Li, M. Ji, H. Xu, Z. Chen and H. Li, Carbon, 2016, 107, 1-10.

30 P. Niu, M. Qiao, Y. Li, L. Huang and T. Zhai, Nano Energy, 2018, 44, 73-81.

31 H. Yu, R. Shi, Y. Zhao, T. Bian, Y. Zhao, C. Zhou, G. Waterhouse, L. Wu, C. Tung and T. Zhang, Adv. Mater., 2017, 29, 1605148.

32 P. Yang, J. Zhao, W. Qiao, L. Li and Z. Zhu, Nanoscale, 2015, 7, 18887-18890.

33 P. Niu, L. Zhang, G. Liu and H. Cheng, Adv. Funct. Mater., 2012, 22, 4763-4770.

34 L. Ma, H. Fan, J. Wang, Y. Zhao, H. Tian and G. Dong, Appl. Catal., B, 2016, 190, 93-102.

35 G. Dong, H. Fan, K. Fu, L. Ma, S. Zhang, M. Zhang, J. Ma and W. Wang, Composites, Part B, 2019, 162, 369-377.

36 J. Qian, J. Yan, C. Shen, F. Xi, X. Dong and J. Liu, J. Mater. Sci., 2018, 53, 12103-12114.

37 Y. Wen, H. Fan, L. Ning, C. Wang, B. Hu, J. Ma and K. Cui, J. Mater. Sci., 2019, 54, 1462-1474.

38 F. Cheng, H. Wang and X. Dong, Chem. Commun., 2015, 51, 7176-7179.

39 S. Hu, L. Ma, Y. Xie, F. Li, Z. Fan, F. Wang, Q. Wang, Y. Wang, X. Kang and G. Wu, Dalton Trans., 2015, 44, 2889-2897.

40 H. Xu, J. Yan, X. She, L. Xu, J. Xia, Y. Xu, Y. Song, L. Huang and H. Li, Nanoscale, 2014, 6, 1406-1415.
41 X. Bai, J. Li, C. Cao and S. Hussain, Mater. Lett., 2011, 65, 1101-1104.

42 N. Nie, L. Zhang, J. Fu, B. Cheng and J. Yu, Appl. Surf. Sci., 2018, 441, 12-22.

43 Q. Xu, B. Cheng, J. Yu and G. Liu, Carbon, 2017, 118, 241249.

44 B. Sun, H. Li, H. Yu, D. Qian and M. Chen, Carbon, 2017, 117, 1-11.

45 J. S. Kim, J. W. Oh and S. I. Woo, Int. J. Hydrogen Energy, 2017, 42, 5485-5495.

46 X. She, J. Wu, J. Zhong, H. Xu, Y. Yang, R. Vajtai, J. Lou, Y. Liu, D. Du, H. Li and P. Ajayan, Nano Energy, 2016, 27, 138-146.

47 G. Liu, G. Zhao, W. Zhou, Y. Liu, H. Pang, H. Zhang, D. Hao, X. Meng, P. Li, T. Kako and J. Ye, Adv. Funct. Mater., 2016, 26, 6822-6829.

48 P. Niu, G. Liu and H. Cheng, J. Phys. Chem. C, 2012, 116, 11013-11018.

49 Y. Kang, Y. Yang, L. Yin, X. Kang, L. Wang, G. Liu and H. Cheng, Adv. Mater., 2016, 28, 6471-6477.

50 Z. Mo, H. Xu, Z. Chen, X. She, Y. Song, J. Wu, P. Yan, L. Xu, Y. Lei, S. Yuan and H. Li, Appl. Catal., B, 2018, 225, 154-161.

51 Y. Li, M. Yang, Y. Xing, X. Liu, Y. Yang, X. Wang and S. Song, Small, 2017, 13, 1701552.

52 Y. Hong, C. Li, Z. Fang, B. Luo and W. Shi, Carbon, 2017, 121, 463-471. 